\title{
Aa. Vv., Dire le mal 4, «Balises. Cahiers de Poétique des Archives \& Musée de la Littérature»
}

\section{Francesca Pagani}

\section{(2) OpenEdition}

1 Journals

\section{Edizione digitale}

URL: http://journals.openedition.org/studifrancesi/5766

DOI: 10.4000/studifrancesi.5766

ISSN: 2421-5856

\section{Editore}

Rosenberg \& Sellier

\section{Edizione cartacea}

Data di pubblicazione: 1 septembre 2011

Paginazione: 456-457

ISSN: 0039-2944

\section{Notizia bibliografica digitale}

Francesca Pagani, «Aa. VV., Dire le mal 4, «Balises. Cahiers de Poétique des Archives \& Musée de la Littérature»», Studi Francesi [Online], 164 (LV | II) | 2011, online dal 30 novembre 2015, consultato il 13 janvier 2021. URL: http://journals.openedition.org/studifrancesi/5766 ; DOI: https://doi.org/10.4000/ studifrancesi.5766

Questo documento è stato generato automaticamente il 13 janvier 2021.

\section{(c) (1)}

Studi Francesi è distribuita con Licenza Creative Commons Attribuzione - Non commerciale - Non opere derivate 4.0 Internazionale. 


\title{
Aa. Vv., Dire le mal 4, «Balises. Cahiers de Poétique des Archives \& Musée de la Littérature»
}

\author{
Francesca Pagani
}

\section{NOTIZIA}

Dire le mal 4, «Balises. Cahiers de Poétique des Archives \& Musée de la Littérature», 13-14, 2009, 344 pp.

1 La rivista «Balises» conclude, con questa miscellanea, il ciclo Dire le mal-composto nell'insieme da quattro corposi volumi - offrendo un articolato percorso che mette in luce quanto la tradizione ha convenzionalmente definito con il termine «Mal» (p. 9), ricercandone le espressioni contemporanee nei vari ambiti artistici, in particolare nella letteratura, nella critica e nelle arti visive. La centralità del tema è d'altra parte attestata da altre significative pubblicazioni di questi ultimi anni, quali Il Male. Esercizi di pittura crudele (a cura di Vittorio Sgarbi, Milano, Skira, 2005) e il terzo numero dei «Cahiers de littérature française» intitolato Le Texte cruel (dirigé par Franca Franchi, Bergamo-Paris, Sestante edizioni-L'Harmattan, 2006).

2 La letteratura novecentesca offre lo spunto a Lambert BARTHÉLÉMY per elaborare Quelques remarques sur le mal dans la fiction contemporaine (pp. 123-134), illustrando la «logique de l'excès » che conduce a « décliner le démoniaque sous formes diverses» ( $p$. 123), in particolare «le mort-vivant, le guerrier-fou et le serial killer» (p. 125). Di altra natura i contributi, dedicati a due grandi interpreti del secolo scorso, di Nabile FARÈs (L'Autre Camus, pp. 25-30) che propone un insolito Albert Camus, definito «l'altro Camus», quale «dernier écrivain colonial», «qui a dit et redit la tragédie coloniale» (p. 28), e di Valentina BIANCHI (Beckett et les frères Van Velde: un art d'incarcération, pp. 115-121), che ritrova in Beckett - in particolare in Fin de partie, En attendant Godot, Pas moi, Oh les beaux jours - una claustrofobica arte della prigionia con assonanze 
riconducibili a quelle espresse dall'arte pittorica dei Van Velde, i cui dipinti suscitarono riflessioni da parte dello stesso Beckett.

3 Le arti visive godono, in questo numero di «Balises», di un'attenzione particolare: Joseph ATTIÉ presenta infatti il Musée d'Emilio Araúzo (pp. 95-113), una raccolta di scatti fotografici che catturano lo spazio e il tempo nella memoria dei frammenti, dei resti, degli scarti abbandonati, in un «musée du temps perdu» appartenente a un ancestrale mondo rurale che resta «même dans l'exil, surtout dans l'exil» (p. 100), mentre cuore della pubblicazione è l'inserto iconografico a colori di Sarah KALINSKI dedicato a Max Jacob («Vivre? À bout de souffle... Bonjour Max Jacob...», pp. 137-184). L'artista presenta svariati ritratti del poeta, molti dei quali ispirati agli ultimi tragici giorni di vita di Jacob, trascorsi nel campo di Drancy: egli è rappresentato prostrato, in preda all'incubo della prigionia, spesso accanto ad un crocifisso o crocifisso egli stesso, e/o marchiato dalla stella rossa di Davide che richiama le sue origini ebree.

Una sezione importante è infine dedicata a Les Bienveillantes di Jonathan Littell, di cui dà conto il pregevole saggio di Joseph BRAMI ("Les Bienveillantes" de Jonathan Littell. Une esthétique de l'insoutenable, pp. 265-313). Nell'intento di "parler sous forme romanesque d'un mal précis, réel, historique: le nazisme » (p. 265), Littell crea un universo in cui il lettore non solo è posto di fronte al male e a una concezione profondamente nichilista della natura umana - «le mal est essentiel à l'homme» (p. 311) - ma è sedotto da una «esthétique de l'insoutenable, tant pour la sensibilité que pour l'intelligence» (p. 267). La guerra e il nazismo si intrecciano al "romanzo familiare" di Max Auer, il personaggio di Littell, un romanzo altrettanto crudele, denso di pulsioni incestuose e omicide. Che la forza di questo romanzo sia, tra l'altro, riconducibile a «sa précision descriptive, qui horrifie et néanmoins rétient», a "sa force narrative qui tout en menant le lecteur au bord de l'épuisement [...] ne l'y laisse jamais sombrer grâce au pouvoir d'une écriture qui retient même quand ce qu'elle rapporte gêne et agâce» (p. 310), è attestato anche dal contributo successivo, Variations (pp. 315-322) di Charles BERKENBAUM, che si compiace nell'esplorare alcuni testi dei molti detrattori di Littell. Soffermandosi in particolare su Les Malveillantes di Blanrue, che, pur estremamente critico nei confronti di Littell, non può esimersi dall'affermare che «l'ouvrage est fascinant par le monde baroque qu'il propose», Berkenbaum giunge a consacrare questo romanzo ponendolo nel solco di una tradizione che, più che barocca, si rivela come espressione piena della contemporaneità: «Les Bienveillantes seraient un roman orphelin, une machinecélibataire» (pp. 319-320). 